\title{
Near-Surface Transport Pathways in the North Atlantic Ocean: Looking for Throughput from the Subtropical to the Subpolar Gyre
}

\author{
IRINA I. RYPINA AND LAWRENCE J. PRATT \\ Woods Hole Oceanographic Institution, Woods Hole, Massachusetts \\ M. SUSAN LOZIER \\ Earth and Ocean Sciences, Nicholas School of the Environment, Duke University, Durham, North Carolina
}

(Manuscript received 10 May 2010, in final form 3 November 2010)

\begin{abstract}
Motivated by discrepancies between Eulerian transport estimates and the behavior of Lagrangian surface drifters, near-surface transport pathways and processes in the North Atlantic are studied using a combination of data, altimetric surface heights, statistical analysis of trajectories, and dynamical systems techniques. Particular attention is paid to the issue of the subtropical-to-subpolar intergyre fluid exchange. The velocity field used in this study is composed of a steady drifter-derived background flow, upon which a time-dependent altimeter-based perturbation is superimposed. This analysis suggests that most of the fluid entering the subpolar gyre from the subtropical gyre within two years comes from a narrow region lying inshore of the Gulf Stream core, whereas fluid on the offshore side of the Gulf Stream is largely prevented from doing so by the Gulf Stream core, which acts as a strong transport barrier, in agreement with past studies. The transport barrier near the Gulf Stream core is robust and persistent from 1992 until 2008. The qualitative behavior is found to be largely independent of the Ekman drift.
\end{abstract}

\section{Introduction}

In educating the public on the role of the ocean circulation in climate, the global circulation is often simplified and presented as a branching "conveyor belt." Transport pathways in this picture are represented in terms of continuous currents, even though it is known that the actual movement of water may take place in eddies and over paths that are intermittent. However, even in the North Atlantic, the most densely sampled major basin in the global ocean, it is difficult to move beyond the conveyor belt model since transport pathways in the upper and lower limbs of the meridional overturning circulation (MOC) are still so poorly understood.

The traditional view (Stommel and Arons 1960) that recently ventilated waters from the subpolar North Atlantic flow southward in a deep western boundary current (DWBC) has recently been contradicted by a study

Corresponding author address: Irina I. Rypina, Physical Oceanography Department, Woods Hole Oceanographic Institution, Woods Hole, MA 02543.

E-mail: irypina@whoi.edu of deep floats (Bower et al. 2009), which shows that the primary southward pathway for these waters lies well offshore. Similarly, the general expectation that waters constituting the upper limb of the MOC are carried continuously into the subpolar gyre via the Gulf Stream/ North Atlantic Current has come under some recent suspicion. Prior studies have shown that the Gulf Stream transports approximately $65 \mathrm{~Sv}\left(\mathrm{~Sv} \equiv 10^{6} \mathrm{~m}^{3} \mathrm{~s}^{-1}\right)$ at Cape Hatteras (e.g., Johns et al. 1995) and that about $20 \mathrm{~Sv}$ of this flow makes its way northward into the subpolar gyre via the North Atlantic Current. However, recent studies based on surface drifters show very little intergyre exchange in the North Atlantic, leaving open the question of how, where, or when the waters of the MOC upper limb enter the subpolar gyre to eventually return to their deep-water formation sites. Clearly, our understanding of how water parcels move as part of the North Atlantic MOC remains unclear. The main thrust of the present paper is to clarify this picture using a combination of data, models, trajectory statistics, and methodology from dynamical systems theory.

Observations of surface drifters in the North Atlantic show surprisingly small connectivity between 
the subtropical and subpolar gyres. Of the drifters deployed south of $45^{\circ} \mathrm{N}$ from 1990 to 2002 , only one reached the subpolar gyre (Brambilla and Talley 2006). At first glance, these observations suggest that the two gyres are completely separated from each other at the surface by a transport barrier. However, because of the limitations of the drifter dataset, it is also possible that surface exchange between the gyres is limited to certain areas or times that were poorly sampled by drifters and/ or occurs on time scales longer than the typical drifter lifetime.

Brambilla and Talley (2006) investigated the possibility that sampling bias (due to short drifter lifetime) or Ekman drift could have led to the surprisingly small number of drifter crossings. They quantified the percentage of actual and simulated drifters, deployed in the rectangular domain (referred to as the Gulf Stream box) from $35^{\circ}$ to $47^{\circ} \mathrm{N}, 78^{\circ}$ to $48^{\circ} \mathrm{W}$, that crossed into the subpolar gyre. Simulated drifters were advected through the drifter-derived mean field with and without the Ekman component and through the mean field with a stochastic perturbation (representing turbulent eddies) superimposed. The authors found that the sampling bias and the Ekman velocity limit the connectivity between the gyres, whereas the stochastic perturbation increases the connectivity. Contributions from the Ekman and turbulent components were estimated to be of the same order and account for only about $5 \%-6 \%$ decrease or increase, respectively, in drifter crossings. The authors were also able to create a set of trajectories with an average life span of 600 days by compositing shorter trajectories, which led to a modest $4 \%$ increase in drifters moving from the Gulf Stream box to the subpolar gyre. Note, however, that these specific numbers apply only to their rectangular launch site and may not be representative of other regions. Even with a $10 \%$ increase in the number of drifters that make it to the subpolar gyre, it is difficult to account for the $20 \mathrm{~Sv}$ (of $65 \mathrm{~Sv}$ at Hatteras) estimated to do so.

According to Bingham et al. (2007), another indication of limited connectivity between the gyres is the loss of meridional coherence of MOC anomalies at about $40^{\circ} \mathrm{N}$, which corresponds roughly to the intergyre boundary. In their modeling study, these authors demonstrated that the loss of coherence could be attributed to the dominance of decadal variability for the zonally averaged northward transport anomalies north of $40^{\circ} \mathrm{N}$, in the subpolar region, compared to the dominance of annual and higher-frequency variability in the subtropical region.

The impact of interannual variability in the North Atlantic surface currents on intergyre exchange was further investigated by Hakkinen and Rhines (2009) using nearly the same drifter dataset as in Brambilla and Talley (2006). These authors separated the observed drifter tracks into three intervals (1991-95, 1996-2000, and 2001-05) and counted the number of drifters moving from the Brambilla and Talley Gulf Stream box to the subpolar gyre during each interval. Their analysis indicated an increase in the intergyre connectivity after 2001, from which they inferred a change in surface currents that opened new pathways from the western subtropical gyre to the subpolar latitudes. Although this conclusion is plausible and supported by observational evidence of an abrupt increase in salinities since 2002 in the Faroe-Shetland Channel and in the Rockall Trough (Holliday et al. 2008), the increased number of crossings into subpolar latitudes since 2001 could also be explained by differences in drifter launch locations before and after 2001. We will elaborate on this point in the next section after presenting our analysis.

Though the interpretation of a mean transport across a fixed section is straightforward, the same is not true for the passage of drifters across that same section. Thus, a reconciliation of Eulerian volume transport estimates with fluid particle trajectories would be required to fully address the conundrum described above. Here, we focus primarily on the Lagrangian view of the subtropical to subpolar exchange in an effort to shed light on these recent observations and leave such reconciliation to a later study. In our study of the near-surface subtropicalto-subpolar fluid exchange in the North Atlantic, a time-dependent near-surface velocity field has been constructed by combining a drifter-derived mean field (similar to that of Brambilla and Talley) with a mesoscale perturbation based on satellite altimetry. The resulting field, which approximates surface velocities over 1992-2008, is described in section 2. Also in section 2, we show results of several simulated drifter release experiments that shed light on the near-surface transport pathways by which subtropical waters flow into the subpolar region. Recent advances in the theory and application of dynamical systems (DS) have been extensively used over the last two decades to clarify the Lagrangian picture of fluid stirring and exchange processes. These methods will be explored in section 3 to complement more traditional analysis based on trajectory statistics. The results also provide some insights into the horizontal diffusivity, including the failure of traditional parameterizations to capture the barrier effect of the Gulf Stream. Because of the complicated time dependence of the flow, transport pathways and processes may vary significantly with time. This issue is addressed in section 4 , where we ask whether the natural variability of surface currents in the North Atlantic can trigger some qualitative changes in the geometry of 


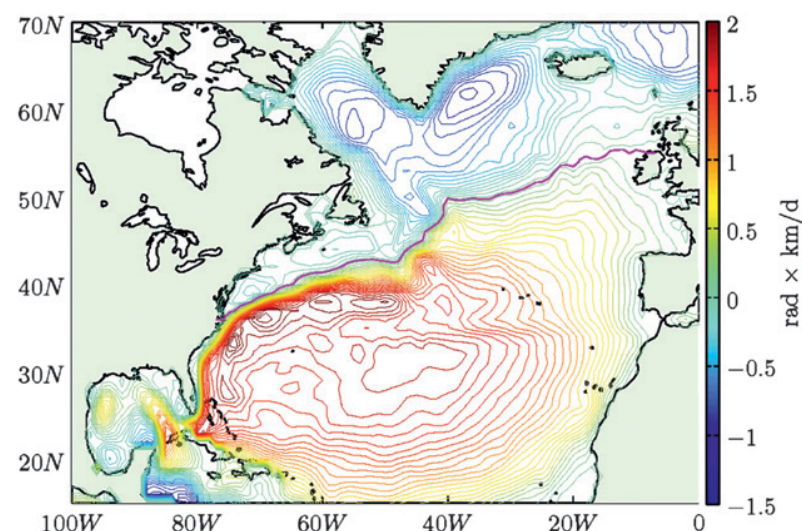

FIG. 1. The steady drifter-based streamfunction $\psi_{0}(\lambda, \theta)$ that describes the mean surface circulation of the North Atlantic. The magenta curve extending across the North Atlantic is the separating streamline.

transport pathways and barriers. Section 5 concentrates on the influence of Ekman drift on the exchange processes. A summary of our studies and conclusions is given in section 6.

\section{Near-surface transport pathways in the North Atlantic: Looking for the subtropical-to- subpolar gyre throughput}

The observation-based model that we have used to study near-surface fluid exchange in the North Atlantic consists of a drifter-derived steady background flow (similar to that of Brambilla and Talley 2006) subject to an altimetry-based (i.e., surface height anomaly) perturbation. This approach was first employed by Rypina et al. (2009) in the Adriatic Sea. Throughout our work we have assumed that the flow is two dimensional and that the streamfunction takes the form

$$
\psi(\theta, \lambda, t)=\psi_{0}(\theta, \lambda)+\psi_{1}(\theta, \lambda, t),
$$

where $(\theta, \lambda)$ are latitude and longitude and the subscripts 0 and 1 denote the steady and the time-dependent part of the streamfunction, respectively. The fluid particle trajectories are given by

$$
\frac{d \lambda}{d t}=\frac{-\partial \psi / \partial \theta}{R \cos \theta} ; \quad \frac{d \theta}{d t}=\frac{\partial \psi / \partial \lambda}{R \cos \theta},
$$

where $R$ is the earth's radius.

The background streamfunction $\psi_{0}(\theta, \lambda)$ was constructed from time averages of spatially binned $\left(1^{\circ} \times 1^{\circ}\right.$ bins) near-surface drifter velocities $u_{\mathrm{dr}}$ and $v_{\mathrm{dr}}$ by writing a finite difference approximation to the equations

$$
\frac{\partial \psi_{0}}{\partial \theta}=-u_{\mathrm{dr}} ; \quad \frac{\partial \psi_{0}}{\partial \lambda}=v_{\mathrm{dr}} \cos \theta,
$$

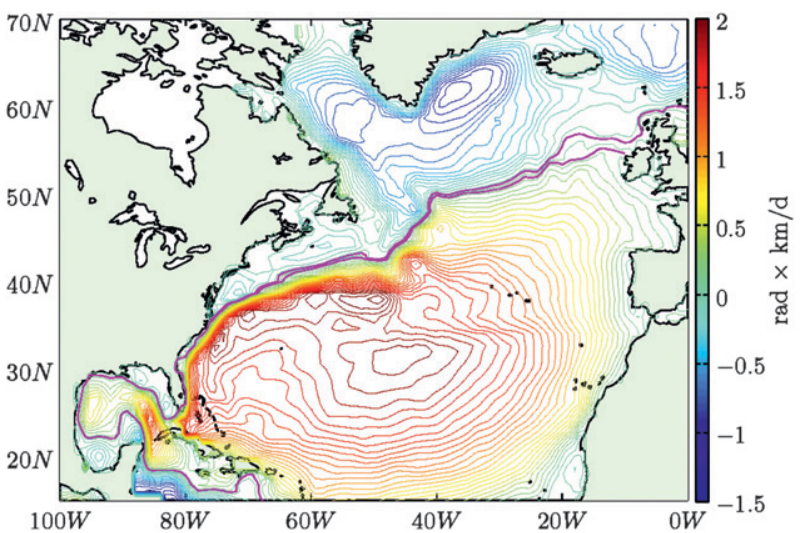

FIG. 2. The streamfunction $\psi_{0}(\lambda, \theta)$ field that takes into account a small near-surface outflow from the North Atlantic into the Arctic.

followed by a least squares fitting procedure. The nonormal flow condition was imposed at the boundary by setting $\psi_{0}=$ const everywhere on land. The resulting streamfunction in Fig. 1 shows two well-defined main gyres, a smaller subpolar and a larger subtropical gyre. The two are separated by a dividing streamline (black curve) that extends from the hyperbolic (saddle type) stagnation point at about $36^{\circ} \mathrm{N}, 76^{\circ} \mathrm{W}$ to the hyperbolic stagnation point at about $55^{\circ} \mathrm{N}, 10^{\circ} \mathrm{W}$. Because this separating streamline prevents throughflow from the subtropical into the subpolar gyre in the mean velocity field, any throughflow that results in the time-dependent field is due entirely to the eddy field. An important property is that the Gulf Stream lies inside the subtropical gyre to the southeast of this separating streamline. (The mean Gulf Stream core was defined as the streamline that has locally the largest average velocity between $25^{\circ}$ and $42^{\circ} \mathrm{N}$, $80^{\circ}$ and $45^{\circ} \mathrm{W}$.)

A slightly different geometrical configuration (Fig. 2) arises if one accounts for a small near-surface flow from the North Atlantic into the Arctic, which brings warm water poleward where it cools and sinks. However, since the two geometrical configurations give similar results in terms of percentage of trajectories that cross from the subtropical to the subpolar gyre, we focus here only on the geometry described above.

To construct an unsteady mesoscale surface velocity field in the North Atlantic, we have superimposed an altimetry-based perturbation $\psi_{1}=(g / f) h(\theta, \lambda, t)$ on $\psi_{0}$ as described by Eq. (1). Here $h$ is an altimetric sea level anomaly, $g$ the gravitational acceleration, and $f(\theta)$ the Coriolis parameter. The corresponding sea level fields cover the time interval from 1992 to 2008 with $\Delta t=7$ days. A plot (Fig. 3) of the 16-yr average kinetic energy for this field suggests that the most energetic eddies occur near the Gulf Stream extension. Although our 


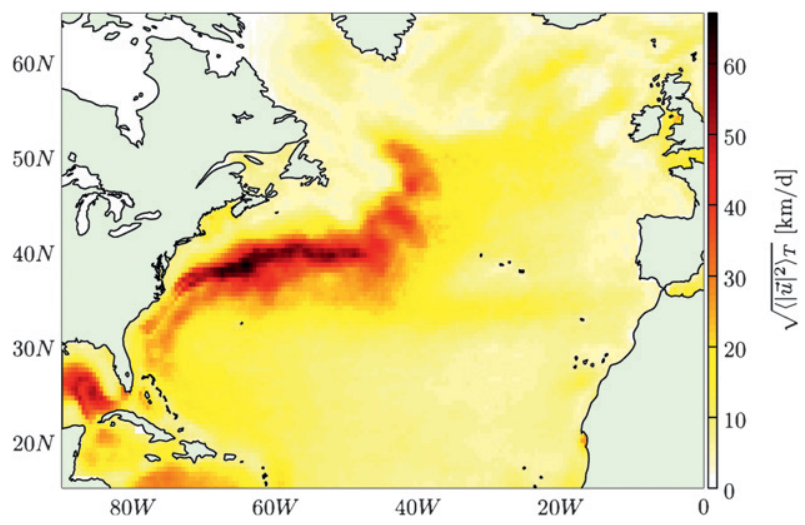

FIG. 3. Square root of the time-averaged eddy kinetic energy computed from altimetric sea surface heights.

observation-based velocity field is entirely based on data, it has some rather obvious shortcomings as a model of the North Atlantic near-surface circulation. These shortcomings include the sparse resolution of both background flow and perturbation in space and time, neglect of transport through various straits, errors in $u_{\mathrm{dr}}$ and $v_{\mathrm{dr}}$ due to the limitations of the drifter dataset, and neglect of the nongeostrophic component in $\psi_{1}$. Despite these limitations, the observation-based model describes fairly well the near-surface mesoscale velocity field of the North Atlantic and its variability. Results of numerical simulations performed using these observation-based velocities are presented in Figs. 4-8, and 11.

To study intergyre exchange, 90 drifters were released once per month during the 12 months starting in October 1992 within a zonal band straddling the Gulf Stream near $34^{\circ} \mathrm{N}$ and tracked for two years (Fig. 4). As explained later in the text we have conducted this analysis for all years in our temporal domain. Here October 1992-September 1993 is shown as a representative year. Also, we chose two year integrations since two years corresponds approximately to the average drifter lifetime and because it matches the integration time previously used by Brambilla and Talley (2006). We have shaded black any trajectory that crosses $55^{\circ} \mathrm{N}$ and taken this as a crude criterion for entering the subpolar gyre. It can be seen that only a few of the trajectories launched in the eastern part of this zonal segment were able to cross $55^{\circ} \mathrm{N}$. This suggests that, at least at the surface, a transport barrier exists that prevents trajectories originating on its offshore side from entering the subpolar gyre. We argue that this barrier may be associated with the instantaneous position of the Gulf Stream core. Because the Gulf Stream shifts in time, its instantaneous core oscillates about its mean position (green curve). Such oscillation may explain the existence of some black launch locations that lie offshore from the green curve in Fig. 4. Our inference about the Gulf Stream core as a transport
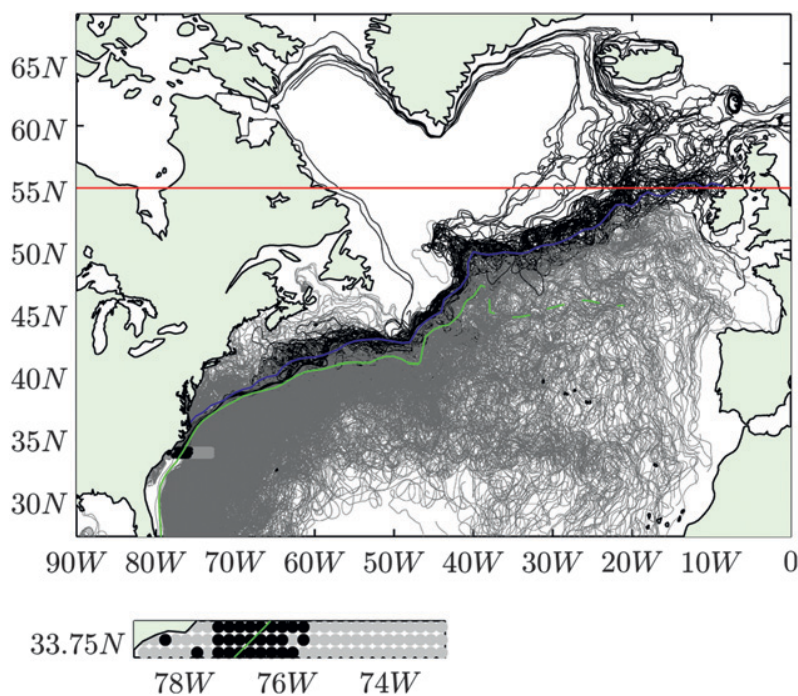

FIG. 4. Two-year simulated drifter tracks in the observation-based system. Drifters were released once per month during the 12 months starting in October 1992 within a zonal band straddling the Gulf Stream near $34^{\circ} \mathrm{N}$. Tracks and release sites are color coded: black for tracks that crossed $55^{\circ} \mathrm{N}$ and gray for tracks that did not. The blue curve is the separating streamline; the green curve approximates the Gulf Stream velocity core of the background flow (dashed where the core is no longer well defined); and red is a zonal line at $55^{\circ} \mathrm{N}$. Colorcoded launch locations are also shown in the small subplot below.

barrier agrees with the observations of Bower et al. (1985) showing limited surface exchange across the Gulf Stream and also with the presence of a strong potential vorticity gradient across the Gulf Stream.

Figure 5 shows regions of the subtropical gyre that participate in the exchange with the subpolar gyre. For a simulated drifter launched at a particular location, this figure shows the probability that the drifter will cross a zonal line at $55^{\circ} \mathrm{N}$ within $2 \mathrm{yr}$. Most of the subtropical gyre is characterized by virtually zero probabilities (white area), meaning that drifters launched there do not make it into the subpolar gyre within 2 yr. Drifters that do reach the subpolar gyre must be launched inside the gray and black funnel-shaped region located onshore of the instantaneous position of the Gulf Stream core. Note that this region is quite narrow to the south of approximately $40^{\circ} \mathrm{N}$ and can easily be missed by a random seeding of drifters. This result suggests an alternative interpretation of the main result of Hakkinen and Rhines (2009): the increased number of drifters crossing from the subtropical to the subpolar region since 2001 may simply indicate that more drifters were deployed inside the funnelshaped area after 2001 than before 2001. Indeed, a visual comparison between the distribution of launch locations before and after 2001 [Fig. 2a in Hakkinen and Rhines (2009)] and the black and gray funnel-shaped region in Fig. 5 suggests this may be the case. 


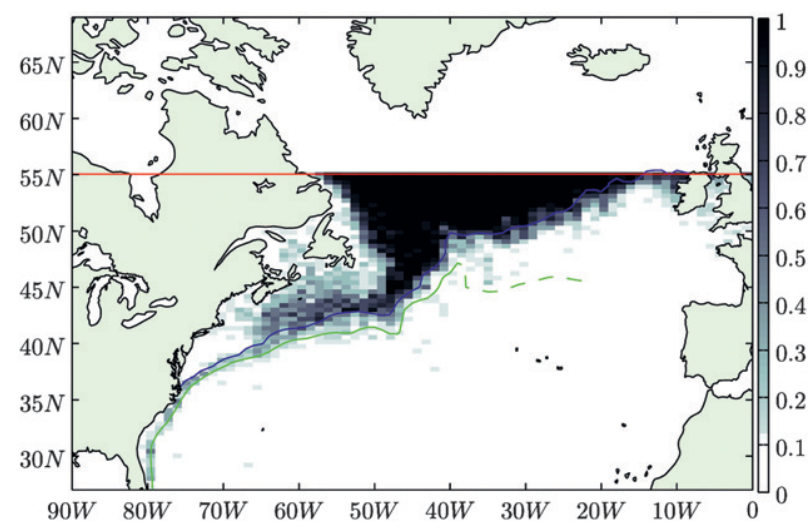

FIG. 5. Probability that a drifter crosses a zonal line at $55^{\circ} \mathrm{N}$ within $2 \mathrm{yr}$ as a function of its launch location in the observationally based model. Simulated drifters were released once per month during the 12 months starting in October 1992 at each model grid point south of $55^{\circ} \mathrm{N}$. The red curve indicates the separating streamline of the background flow; the green curve approximates the Gulf Stream core of the background flow; and the red line indicates a zonal line at $55^{\circ} \mathrm{N}$.

In the previous figure, we launched simulated drifters once per month during the 12 months starting in October 1992. To check that the results would not change for other years, we have done a more extensive calculation, where simulated drifters were launched in a subdomain of the North Atlantic $\left(25^{\circ}-46^{\circ} \mathrm{N}, 83^{\circ}-40^{\circ} \mathrm{W}\right)$ once per month during 14 years (1992-2006). The resulting probability map is shown in Fig. 6a. As in Fig. 5, drifters that reach subpolar latitudes within $2 \mathrm{yr}$ are launched mostly inside the funnel-shaped region onshore of the Gulf Stream core. However, some very small but nonzero probabilities (darkest blue) occur in the interior of the subtropical gyre. Trajectories of simulated drifters corresponding to the nonzero probabilities offshore from the Gulf Stream core in Fig. 6a are illustrated in Fig. 6b. Many of these trajectories recirculate clockwise, enter the Gulf Stream near the Straits of Florida, and then flow through the funnel into the subpolar gyre. Others are entrained into the Gulf Stream along its seaward extension, a sign of a vigorous eddy field.

In the previous figures, we have used a rather restrictive criterion, a zonal line at $55^{\circ} \mathrm{N}$, for the intergyre boundary. An alternative way to define the intergyre boundary is to use the separating streamline of the steady flow. This criterion is less restrictive because some trajectories may cross this separatrix briefly at some location but then cross back into the subtropical gyre at some later time, staying always to the south from $55^{\circ} \mathrm{N}$. Note also that the northernmost point of the separating streamline reaches $55^{\circ} \mathrm{N}$ - the latitude used as a crude criterion for entering the subpolar gyre in Figs. 4 and 5. A map showing probability for a simulated drifter launched at a particular location to cross the separating streamline
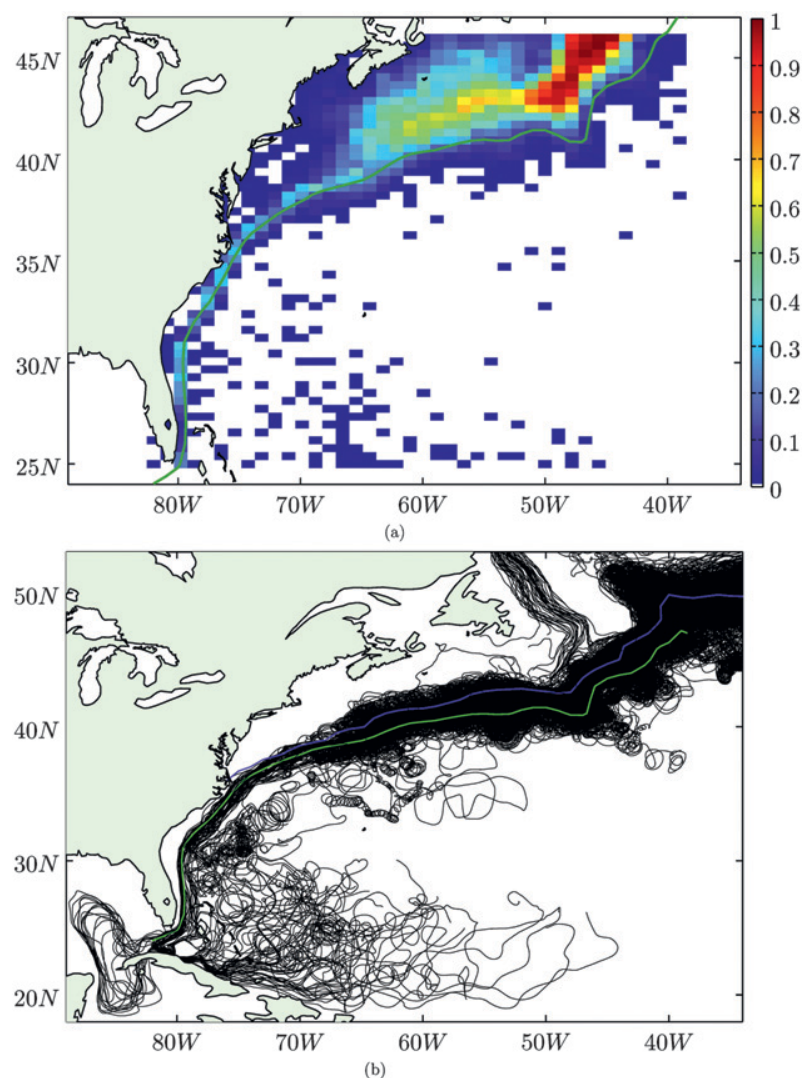

FIG. 6. (a) As in Fig. 4 but for simulated trajectories launched during 14 years (1992-2006). (b) Trajectories of drifters corresponding to the nonzero probabilities offshore from the Gulf Stream core in Fig. 5 a.

within $2 \mathrm{yr}$ is plotted in Fig. 7. As in Fig. 5, most drifters that cross the separating streamline are launched in the narrow dark region located inshore of the Gulf Stream core. However, more launch locations inside the subtropical gyre are characterized by small but nonzero probabilities in Fig. 7 than in Fig. 5. These correspond to drifters that briefly cross the separating streamline but than cross back and recirculate in the subtropical gyre, staying always to the south from $55^{\circ} \mathrm{N}$.

Figures 4-7 show results with 2-yr integration times; results with longer integration times are shown in Fig. 8. This figure shows an estimate of the "cross time" $T_{\text {cross }}$, the time needed for a simulated drifter launched at a particular location to cross a zonal line at $55^{\circ} \mathrm{N}$. Values of $T_{\text {cross }}$ are color coded from blue to red (small to large $T_{\text {cross }}$ ); black indicates launch locations of drifters that did not cross $55^{\circ} \mathrm{N}$ by the end of 2008 (i.e., $T_{\text {cross }}>$ $16 \mathrm{yr}$ ). Several interesting conclusions can be drawn from this figure: first, the blue funnel-shaped region with cross times $T_{\text {cross }} \leq 2$ yr generally resembles the nonzeroprobability region shown in the top panel of Fig. 5. The nozzle of the blue funnel in Fig. 8, however, does not 


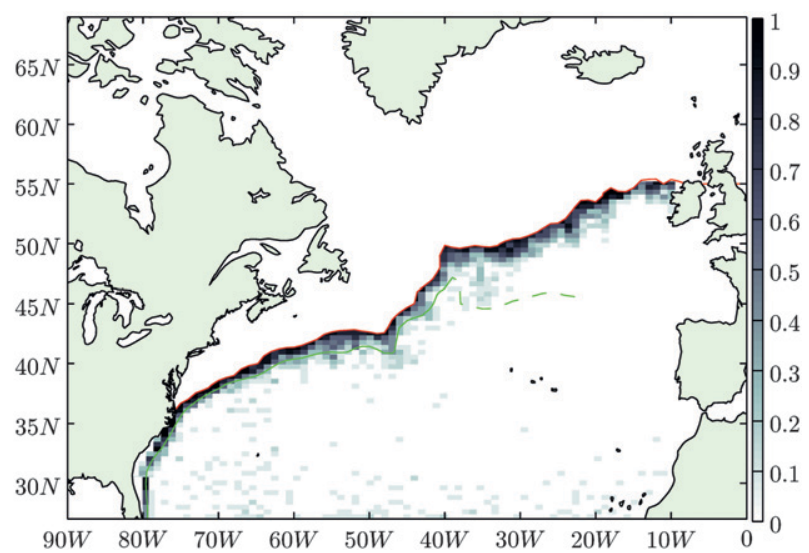

FIG. 7. Probability that the drifter crosses a separating streamline (red curve) within $2 \mathrm{yr}$ as a function of drifter's launch location in the observationally based system. Simulated drifters were released once per month during the 12 months starting in October 1992. The green curve approximates the Gulf Stream core of the background flow.

show up as clearly as in the probability map because we have only launched trajectories once to produce Fig. 8 rather than repeatedly releasing trajectories as in Fig. 5. Second, most of the interior of the subtropical gyre is characterized by very long $T_{\text {cross }}>16 \mathrm{yr}$. Third, the region centered at about $41^{\circ} \mathrm{N}, 70^{\circ} \mathrm{W}$, between the North American coast and the Gulf Stream, has intermediate values of $T_{\text {cross }} \simeq 9 \mathrm{yr}$. Simulated drifters recirculate in this area several times before they are eventually entrained into the western edge of the Gulf Stream and then rapidly transported to the northeast. Lagrangian flow patterns in this region have been studied by Gawarkiewicz and Linder (2006) using near-surface drifters. They observed the same qualitative behavior that was described above (several recirculations followed by the entrainment) in the $15 \%$ of drifters used in their studies.

To compare the results obtained from analyzing simulated drifters in the observation-based model against real drifters, we have performed statistical analysis of satellite-tracked surface drifting buoy trajectories from the Global Drifter Program (GDP) (http://www.aoml. noaa.gov/phod/dac/index.php). A spaghetti diagram showing all available drifter tracks in the North Atlantic from 1992 until 2009 is shown in Fig. 9a. Figure 9b shows drifter tracks that start below and end above the separating streamline (magenta curve). Although the GDP dataset is very rich, it is still insufficient to produce probability maps akin to Fig. 5 or 7. It is possible, however, to divide the domain into $1^{\circ} \times 1^{\circ}$ bins and for each bin compute a probability that a drifter, which is deployed below the separating streamline and which passes through that bin, will end above the separating streamline. The resulting map is shown in Fig. 9c. This figure bears a qualitative resemblance to Fig. 7 in that most of

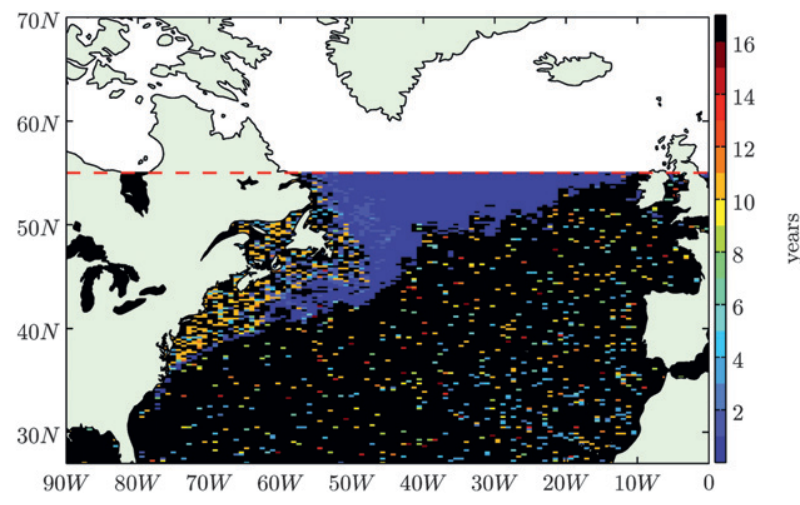

FIG. 8. Time for a simulated drifter to cross a zonal line at $55^{\circ} \mathrm{N}$ as a function of drifter launch location in the observationally based system. Black corresponds to times longer than $16 \mathrm{yr}$. The dashed red line shows a zonal line at $55^{\circ} \mathrm{N}$

the subtropical gyre interior is white, indicating that none of the GDS drifters passing through this region ended up above the separating streamline. GDP drifters that did end up above the separating streamline flowed through the colored region. The agreement with Fig. 7 is especially good in the southwestern part of the subtropical gyre where the eastern boundary of the blue region coincides almost exactly with the mean position of the Gulf Stream core (green curve), forming the nozzle of the funnel as in Fig. 7. The agreement is less clear in the Gulf Stream extension region where the blue region of Fig. 9c extends farther offshore from the Gulf Stream core compared to the gray nonzero-probability region in Fig. 7.

\section{The dynamical systems view on near-surface intergyre exchange in the North Atlantic}

An alternative means of identifying transport pathways and mechanisms for exchange between two gyres, quantifying the exchange, and mapping out barriers to exchange is provided by the dynamical systems (DS) analysis. Much has been written about these techniques, and the reader is referred to the introductions in Deese et al. (2002) and Rypina et al. (2010), both aimed at an oceanographic audience. More rigorous discussions are provided in Mancho et al. (2006) and Samelson and Wiggins (2006). Other publications that have good introductory material and explore exchange processes between oceanic gyres or across jets include Rogerson et al. (1999) and Rypina et al. (2009). Here we provide a limited review that should allow the new reader to understand the specifics of our results.

Consider an idealized, steady, divergence-free, horizontal velocity field consisting of a subtropical and a subpolar gyre (Fig. 10a) between two slippery boundaries. We will assume that there is no exchange between 


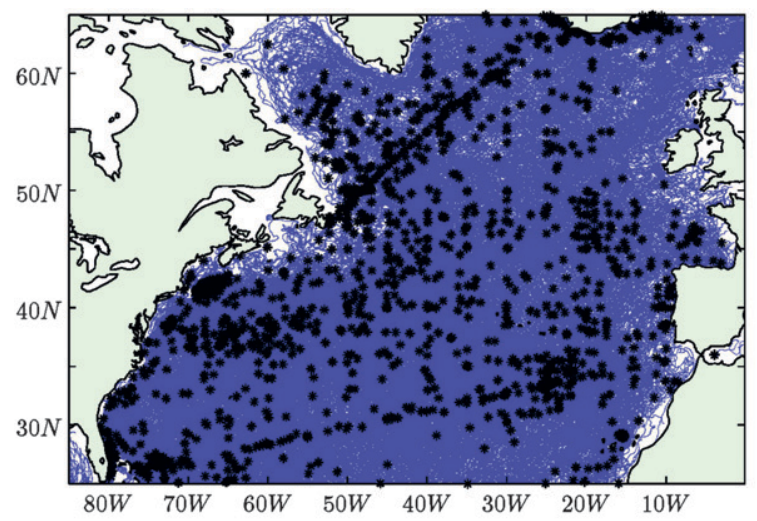

(a)

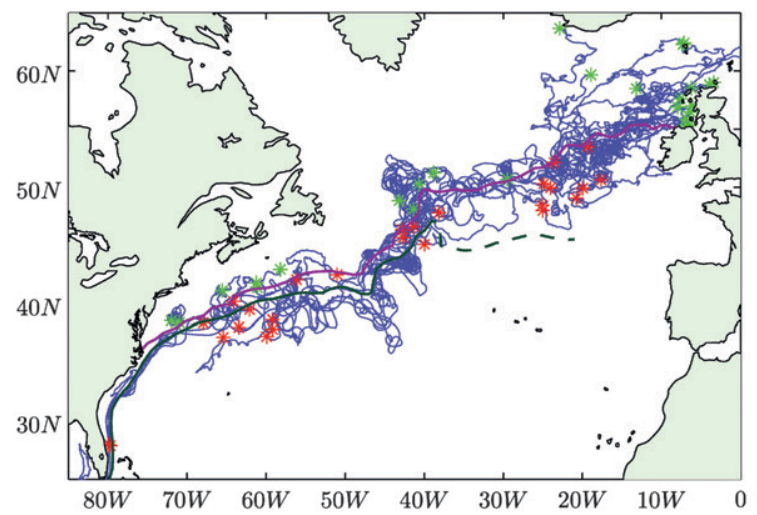

(b)

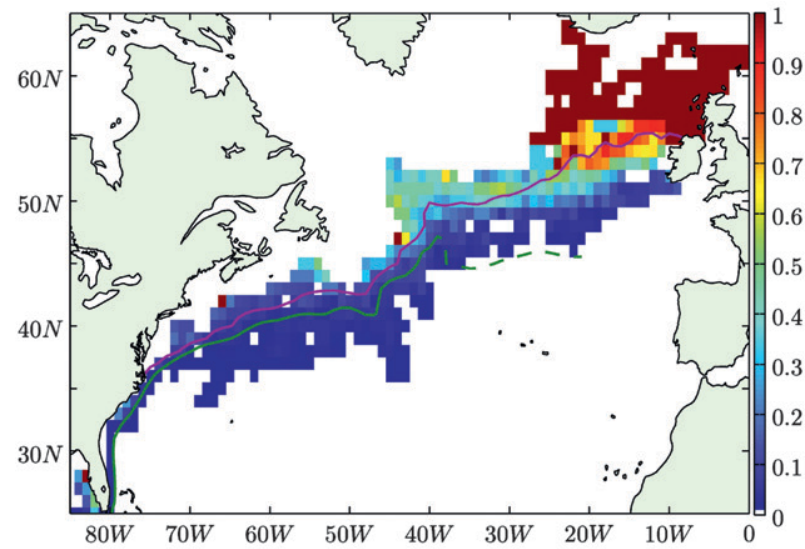

(c)

FIG. 9. (a) Trajectories of drifters from the Global Drifter Program (GDP) array. Black dots show launch positions and positions where drifters entered the domain. (b) Trajectories of drifters that start below and end above the separating streamline (magenta curve); the mean Gulf Stream core is shown by the dark green curve. Launch positions and ending positions are shown by red and green asterisks, respectively. (c) For each bin, the color indicates the probability that a drifter, which is deployed below the separating streamline and passes through that bin, will end above the separating streamline.

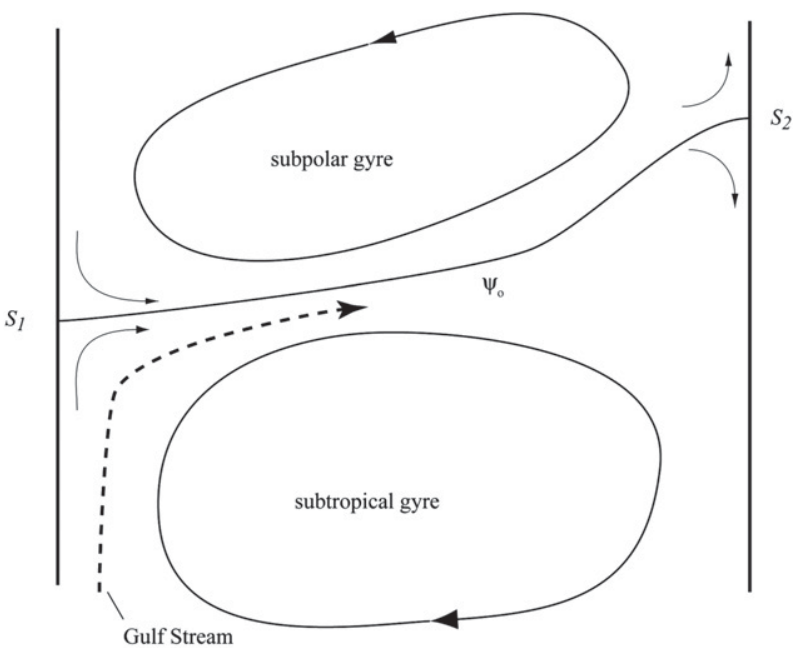

(a)

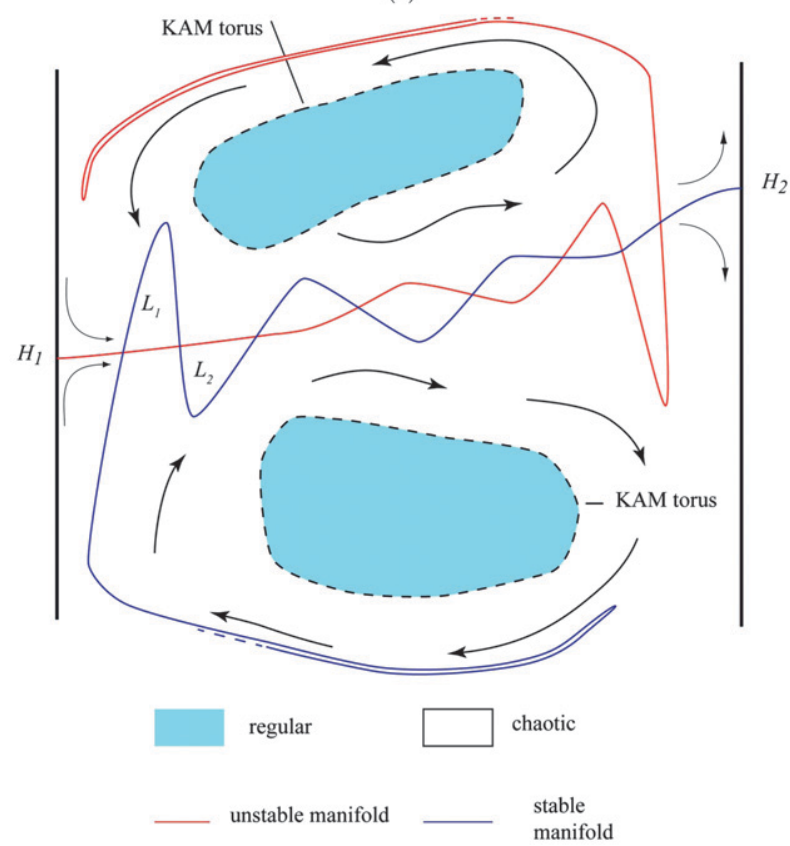

(b)

FIG. 10. Schematic diagram illustrating hyperbolic trajectories, stable and unstable manifolds, and regular regions in a timedependent two-gyre system.

the gyres and that the two are separated by a streamline that connects to the bounding continents. Hyperbolic (saddle type) stagnation points $S_{1}$ and $S_{2}$ exist where the streamline contacts the slippery boundaries. The flow converges in the alongshore direction and diverges in the offshore direction about $S_{1}$; the opposite is true at $S_{2}$. This picture serves as a cartoon for the more complex mean streamfunction map of Fig. 1.

DS analysis can be used to describe the picture that arises if a time-dependent perturbation such as an eddy or wave field, or simply a large scale oscillation of the 
gyres, is added to the steady flow. In particular, it can be shown that material exchange between the gyres will generally occur and that the volumetric exchange rate, which can be thought of as an eddy flux, can be quantified. Key to this picture are several material objects: hyperbolic trajectories, their stable and unstable manifolds, and Kolmogorov-Arnold-Moser (KAM) tori. Loosely speaking, hyperbolic trajectories refer to distinguished fluid parcels (or parcel trajectories) about which exponential convergence and divergence occur, much the same as for hyperbolic stagnation points. In the time-varying version of the flow (Fig. 10b) the hyperbolic trajectories $\mathrm{H}_{1}$ and $\mathrm{H}_{2}$ would often move back and forth along the slippery boundary but remain in the vicinity of the original stagnation points. They would approach $S_{1}$ and $S_{2}$ if the timedependent perturbation were gradually quenched.

If one introduced a small patch of red nondiffusive dye at about $\mathrm{H}_{1}$, the patch would contract in the alongshore direction and stretch in the offshore direction. Eventually the patch would become stretched into the thin filament extending offshore from $\mathrm{H}_{1}$ and penetrate far into the interior of the flow. If the size of the initial patch were shrunk, this filament would narrow down to take the form of a material contour containing fluid that diverges from $\mathrm{H}_{1}$. This moving contour is the unstable manifold of $\mathrm{H}_{1}$ and is depicted by the red curve in Fig. 10b. The unstable manifold is similar to the separating streamline of the steady flow (Fig. 10a), but unlike the separating streamline, it generally does not transect the basin and contact the eastern boundary but instead wiggles and wraps endlessly about the interior.

At the eastern boundary, the motion is toward the hyperbolic trajectory $\mathrm{H}_{2}$ from offshore so that dye introduced in the vicinity of $\mathrm{H}_{2}$ would simply spread along the slippery boundaries. However, if blue dye was introduced and time was reversed, the dye would move offshore from $\mathrm{H}_{2}$ and form a filament approximating the stable manifold of $\mathrm{H}_{2}$ (blue curve in Fig. 9b). The stable manifold consists of all the material that approaches $\mathrm{H}_{2}$ asymptotically in time. This manifold typically intersects with the unstable manifold of $\mathrm{H}_{1}$ at numerous, and sometimes infinitely many, points. The fluid contained in the lobes that are formed between the intersections, bounded by segments of the stable and unstable manifolds, is participating in exchange between the subtropical and subpolar gyres. For example, lobe $\mathrm{L}_{1}$ in Fig. $10 \mathrm{~b}$ carries fluid from the subpolar into the subtropical gyre, whereas lobe $\mathrm{L}_{2}$ returns fluid to the subpolar gyre. For this reason, the objects in question are often referred to as turnstile lobes (Samelson and Wiggins 2006). If an individual lobe is followed, that lobe will become stretched into a thin filament that will eventually be folded and stretched again. It can also be shown that the fluid trajectories within the turnstile lobes are chaotic and that they experience separation from each other at a rate that is exponential in time.

The exponential stretching and folding, as well as the fluid transport and exchange described above, will act over regions that are covered by the intersecting manifolds. However, these regions need not cover the entire fluid domain. Certain trajectories of the steady circulation may remain regular (nonchaotic) in the presence of the time-dependent perturbation. They can be thought of as barriers to chaotic transport. The celebrated KAM theorem (Sevryuk 2007) predicts the presence in the time-dependent flow of material contours composed of fluid whose trajectories are regular. In the example shown, these KAM tori would typically consist of closed contours lying within the recirculations. The blue patches of Fig. 10b represent regions of regular Lagrangian motion and are separated from the surrounding chaotic regions by KAM tori. As the time-dependent perturbation increases in amplitude, the blue regions may shrink and eventually disappear. A particularly strong type of barrier is expected to occur near the shearless trajectory of the background flow, that is, near the trajectory of the fluid parcel that moves, in some average sense, at the same speed as parcels slightly to the sides. Material contours near the core of a meandering jet, where the shear is zero, can be examples of such strong KAM stability (Rypina et al. 2007). The Gulf Stream core is an obvious candidate as it contains trajectories that are shearless, at least over a finite length.

The formal analysis leading to the definition and existence of hyperbolic trajectories, stable and unstable manifolds, and KAM tori is strictly valid under a number of conditions, including weak perturbation strength, two-dimensional, divergence-free velocity fields, and existence of the velocity field over infinite time. In geophysical fluid dynamics, these ideas are commonly applied to observed and modeled velocity fields that are divergent, contain large perturbations about a mean, and are known only over finite time. Despite these formal violations, it is possible to find within certain flow fields "effective manifolds"-material contours that resemble or approximate the manifolds described in textbook examples. They can provide similar insights into transport, exchange, and stirring processes. This type of analysis is most straightforward and useful when the underlying geometry of the flow persists over a time scale long compared to the trajectory time scale. In more formal terms, one would like the Lagrangian time scale $T_{\mathrm{L}}$ of motion (here the typical winding time of a fluid parcel about the gyres) to be much shorter than the Eulerian time scale $T_{\mathrm{E}}$ (here the time over which distinct gyres exist). A more formal discussion is provided by Haller and Poje (1998). 


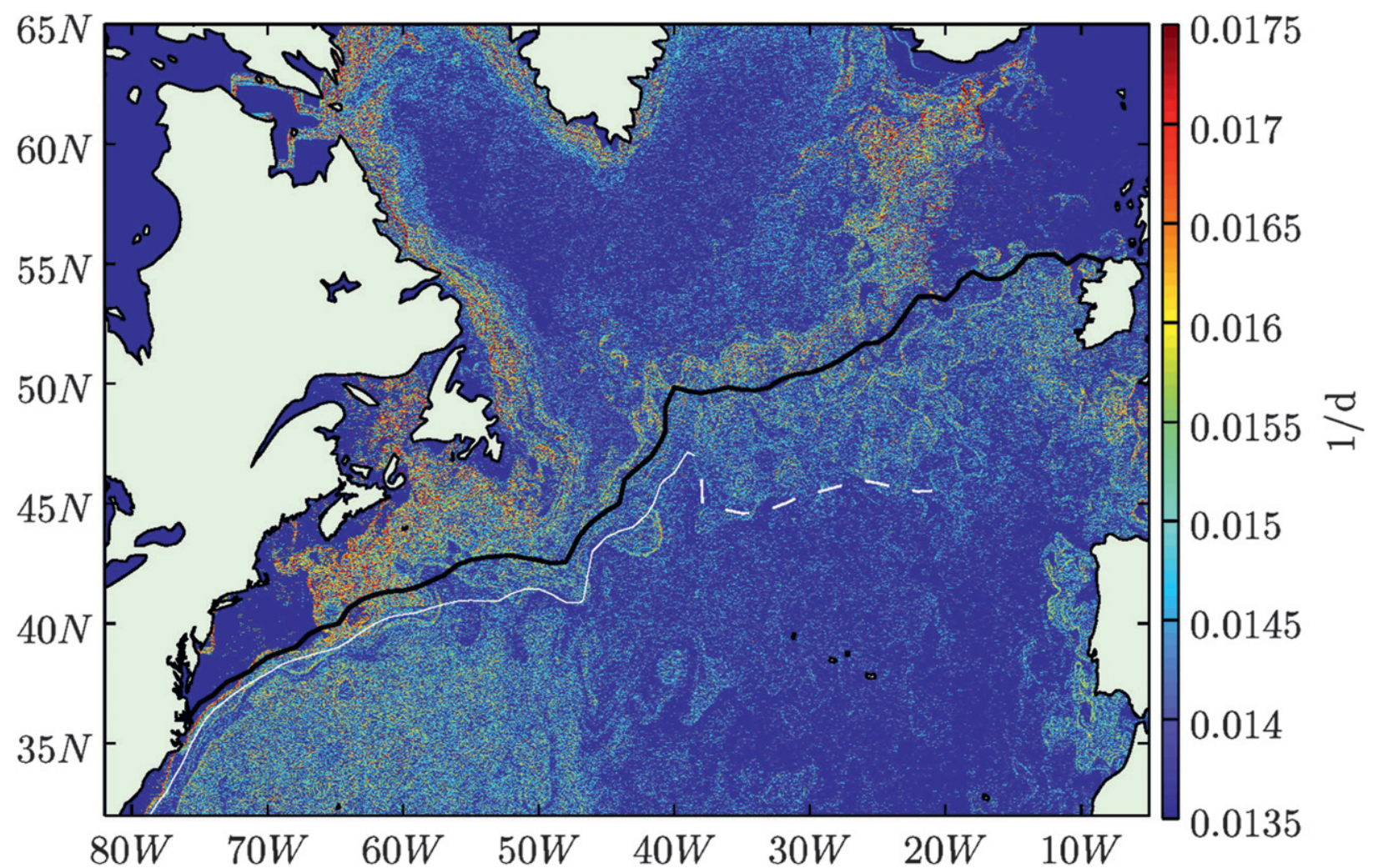

FIG. 11. Forward-time FTLEs on 6 Jan 1993 with a 2-yr integration time. Yellow/red colors indicate chaotic regions, and blue colors indicate more regular regions. The black curve indicates the separating streamline of the background flow; the white curve approximates the Gulf Stream core of the background flow.

Nearly all past oceanographic applications of Lagrangian DS analysis have been to idealized models or to realistic circulations of limited scale, such as Monterey Bay (Coulliette et al. 2007; Shadden et al. 2009), the Philippine Archipelago (Rypina et al. 2010), the Mediterranean Sea (d'Ovidio et al. 2004; d'Ovidio et al. 2009), the Gulf of Mexico (Olascoaga et al. 2006; Kuznetsov et al.2002), and the Adriatic Sea (Rypina et al. 2009). The validity of the approximation $T_{\mathrm{L}} / T_{\mathrm{E}} \ll 1$ is rarely discussed in these studies, though some involve analysis of coherent gyres or eddies whose basic geometry remains intact for lengthy periods. Our study of the subpolar and subtropical gyres differs markedly from earlier work in both scale and in spatial and temporal complexity. Although the major gyres themselves persist over time scales that can be considered infinite for all practical purposes, the mesoscale eddy field has its own set of hyperbolic trajectories and attendant manifolds. The eddies may merge or break up on time scales much less than the gyre winding time and, perhaps, even less that the winding time for an eddy. Therefore, one should not expect to see a picture of exchange as clean as what is described in Fig. 10, nor is it clear whether manifolds computed by conventional methods have any meaning. Another factor that complicates our analysis is the complexity of the unperturbed flow (Fig. 1), where one can see numerous small gyres or eddies, as well as associated hyperbolic stagnation points, within the subtropical and subpolar gyres. So, underlying geometry is considerably more complex than what Fig. 10a suggests.

Despite these difficulties, we have made a formal calculation of manifold structures to determine what useful information, if any, the resulting pictures might yield. In this respect, out analysis is a test to determine whether DS analyses are of any use whatsoever on the scale of major ocean gyres. The most common means of finding stable and unstable manifolds in a numerically specified flow field is through the use of finite time Lyapunov exponents (FTLEs) (Haller 2001a,b, 2002; Shadden et al. 2005; Lekien and Ross 2010). The FTLE is a measure of the maximum separation rate between a trajectory and its close neighbors, averaged over a finite time [see Eq. (12) in Shadden et al. (2005)]. The separation is measured beginning at a particular time and extending forward in time a certain period: $2 \mathrm{yr}$ in our case. The maximum average rate of exponential separation between a trajectory beginning at position $(\theta, \lambda)$ at $t=t_{0}$, and the neighboring trajectories is then computed over a fine grid of 
initial positions. The resulting separation rate (FTLE) field for $t=t_{0}$ can then be contoured or color shaded (e.g., Fig. 11). Under the conditions stated above, including the time scale separation $T_{\mathrm{L}} / T_{\mathrm{E}} \ll 1$, stable manifolds will present themselves as ridges representing maximum values of this plot. (A similar procedure, implemented with the backward time integration from $t_{0}$, gives unstable manifolds.)

Plots of stable and/or unstable manifolds based on smaller scale, coherent ocean features, often show long, smooth manifold structures. Examples include Figs. 3 and 9 in Rypina et al. (2010). Our Fig. 11, which is based on a 2-yr, forward-time integration beginning on 6 January 1993 is markedly different. The regions to the north and south of the Gulf Stream between $80^{\circ}$ and $50^{\circ} \mathrm{W}$, which include the Gulf Stream recirculations, have high but grainy distributions of FTLE. It is difficult to distinguish individual manifolds or turnstile lobes within these areas. High, grainy distributions also exist in the general areas of the Gulf Stream extension and North Atlantic Current, and along the coastal boundaries. All of these areas are marked by high rates of trajectory separation, implying enhanced stirring, and by a lack of the type of organization present in smaller scale examples. The interiors of the subtropical and subpolar gyres are marked by low values of the FTLE (dark blue), which is characteristic of more regular (less chaotic) regions in simpler examples. Even more striking is the meandering, dark blue ribbon apparently corresponding to the Gulf Stream position on 6 January 1993. (The white curve indicates the position of the Gulf Stream core, or velocity maximum, for the steady background flow.) So, although the Gulf Stream edges contain appreciable horizontal velocity shear, the FTLE values are low, as they would be for a KAM tori-more particularly for a KAM tori composed of shearless trajectories. Thus, Fig. 11 strongly suggests that the Gulf Stream acts as a strong, persistent barrier separating regions of rapid stirring. This barrier is most prominent in the western portion of the North Atlantic.

The chaotic region (area of high but grainy distributions of FTLEs) that spans the subtropical/subpolar gyre boundary (black curve in Fig. 11) can be connected to the probability map in Fig. 7. Within this chaotic zone, drifters are free to wonder and possibly move between the gyres, so some drifters launched within this chaotic zone to the south of the black curve will make it into the subpolar gyre. A glance at the probability distributions in Fig. 7 supports this interpretation and shows some nonzero probability values in this area. However, oneto-one correspondence between the chaotic regions and the nonzero-probability region should not be expected because 1) the FTLE field shows a snapshot for a

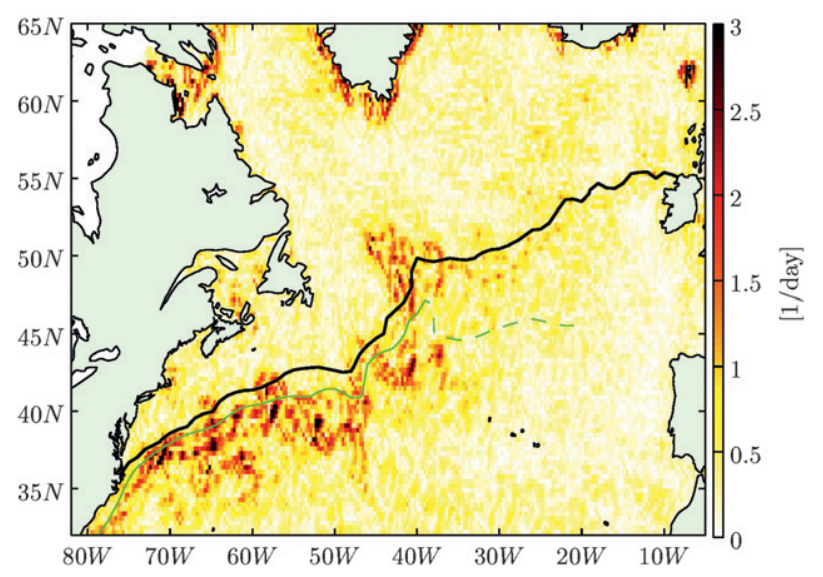

FIG. 12. Deformation rate $D$ on 6 Jan 1993. The black curve indicates the separating streamline of the background flow; the green curve approximates the Gulf Stream core of the background flow.

particular date whereas the probability map was computed using 12 monthly drifter releases and 2) drifters launched within the chaotic zone may but not necessarily need to cross the intergyre boundary, so the corresponding launch location may, but not necessarily, need to correspond to a nonzero probability in the probability plot.

Although individual manifolds and turnstile lobes are difficult to distinguish in Fig. 11, the overall picture of two gyres with weakly stirred interiors and rapidly stirred outer regions, separated by a strong meandering barrier, seems to hold. It is noteworthy that this picture is quite generic and can be found in many investigations of chaotic transport between two gyres (e.g., Poje and Haller 1999). So, although the theory is applied well beyond its formal range of validity, the general picture that emerges follows the textbook examples. Quantitative results, such as turnstile lobe fluxes, are out of the question.

The thin, dark blue ribbon of flow that meanders through the rapidly stirred region between $80^{\circ}$ and $50^{\circ} \mathrm{W}$ is striking, and at odds with commonly used measures of eddy diffusivity. For example, Visbeck et al. (1997) assumes that the diffusion of passive tracers can be parameterized by a transfer coefficient that is proportional to the eddy velocity multiplied by the eddy length scale, $\kappa \propto u_{\text {eddy }} l$. The eddy kinetic energy distribution (Fig. 3), which suggests a maximum $u_{\text {eddy }}$ near the Gulf Stream extension, together with the observation that the largest eddies tend to occur in this region, suggest that $\kappa$ is largest in this region. The Smagorinsky (1963) parameterization, commonly used in GCMs (e.g. Spall et al. 2008), makes the horizontal eddy viscosity proportional to the norm of the deformation tensor, 


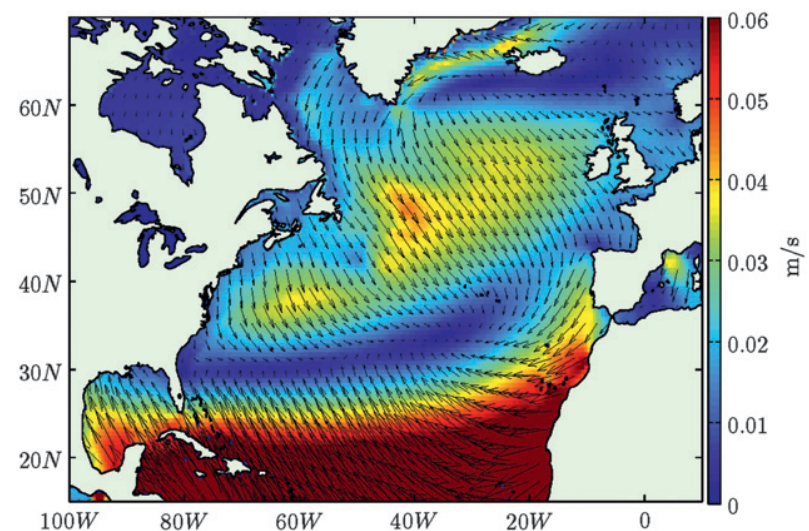

FIG. 13. Mean Ekman velocities.

$D \propto \sqrt{\left(\partial_{x} u-\partial_{y} v\right)^{2}+\left(\partial_{x} v+\partial_{y} u\right)^{2}}$. The spatial distribution of $D$ on 6 January 1993 shows maximum values near the Gulf Stream region (Fig. 12). Thus, both parameterizations miss the effect of the transport barrier near the Gulf Stream core and result in spuriously large momentum and/or tracer transfer rates in this area.

\section{How robust are the near-surface exchange pathways and barriers in the North Atlantic?}

All simulations described above (except those described in Fig. 6) used perturbation fields from 1992 to 1994. To test whether during other years the eddy field can get sufficiently energetic to break the transport barrier associated with the Gulf Stream core, we have repeated simulated drifter releases for years 1993-2006 and computed probability maps akin to Fig. 5. All of the resulting maps (not shown) are qualitatively similar: the region onshore from the Gulf Stream core is gray and black, whereas most of the subtropical gyre is predominantly white. This suggests that the barrier near the Gulf Stream core holds persistently from 1993 until 2006.

To quantify the critical perturbation strength required to break the barrier at the Gulf Stream core, we have artificially elevated the level of the kinetic energy associated with the altimetric eddy field by multiplying $\psi_{1}(\theta$, $\lambda, t)$ in Eq. (1) by $\varepsilon$. Here $\varepsilon=1$ corresponds to the true (real) altimetric eddy field, while $\varepsilon>1$ corresponds to the artificially enhanced eddy field. [Since the ratio of the time-averaged integrated kinetic energy associated with $\psi_{1}$ to the integrated kinetic energy associated with $\psi_{0}$ is of order $O(1), \varepsilon$ can be interpreted as a square root of the ratio of the time-averaged integrated eddy kinetic energy to the integrated mean kinetic energy.] Analysis of simulated trajectories suggest that the barrier near the

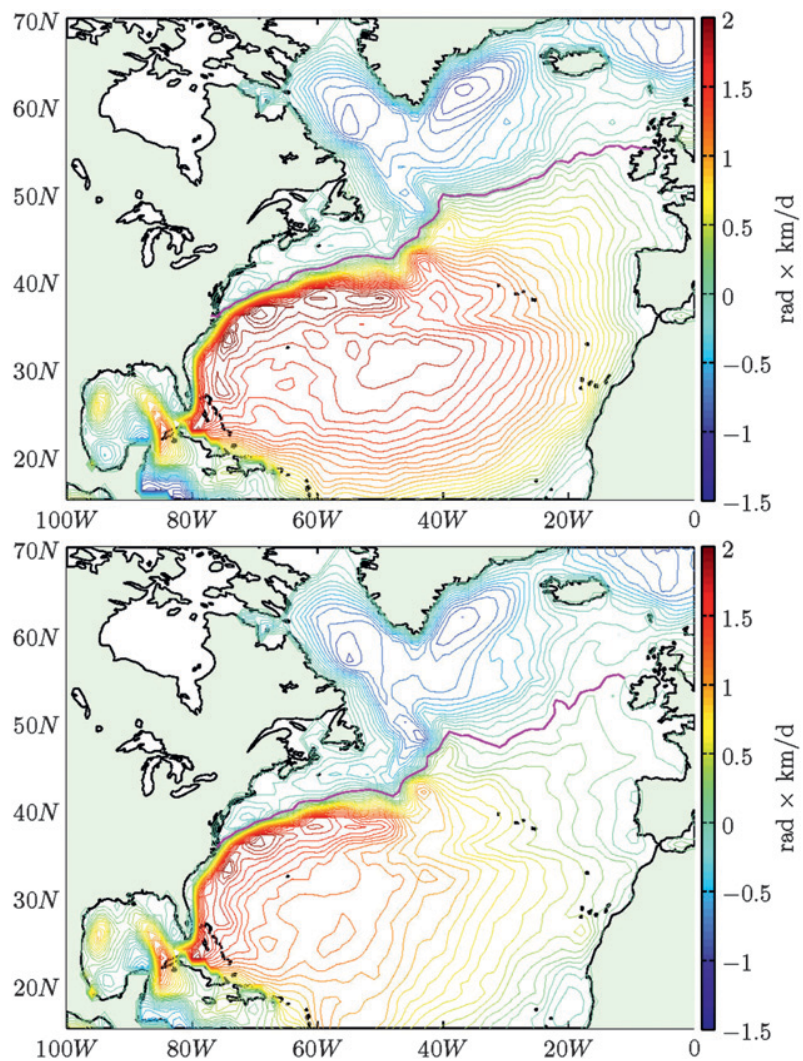

FIG. 14. The streamfunction $\psi_{0}(\lambda, \theta)$ field: (top) Ekman inclusive (as in Fig. 2) and (bottom) Ekman removed.

Gulf Stream core breaks down at $\varepsilon_{\mathrm{cr}} \approx 2.3$; that is, for $\varepsilon>2.3$ there is no spatial gradient near the Gulf Stream core in the corresponding probability maps. The critical value of the perturbation strength is sufficiently larger than the interval of $\varepsilon \in[0.91,1.26]$ associated with the natural variability in the North Atlantic, suggesting once again that the transport barrier near the Gulf Stream core should hold under commonly encountered conditions.

\section{Effect of the Ekman velocities}

In this section, we explore the influence of the Ekman velocities on the near-surface subtropical to subpolar fluid exchange in the North Atlantic. The steady background streamfunction $\psi_{0}$, which has been used in the previous sections, was derived from drifter velocities $u_{\mathrm{dr}}$ and $v_{\mathrm{dr}}$. In this section, we construct the new Ekmanremoved background streamfunction $\hat{\psi}_{0}$ by subtracting the mean Ekman velocity $u_{\mathrm{Ek}}$ and $v_{\mathrm{Ek}}$ from $u_{\mathrm{dr}}$ and $v_{\mathrm{dr}}$ before applying the least squares procedure. The mean Ekman velocity field (Fig. 13) was estimated using Quick Scatterometer (QuickSCAT) wind stresses and the Ralph and Niiler (1999) formula 


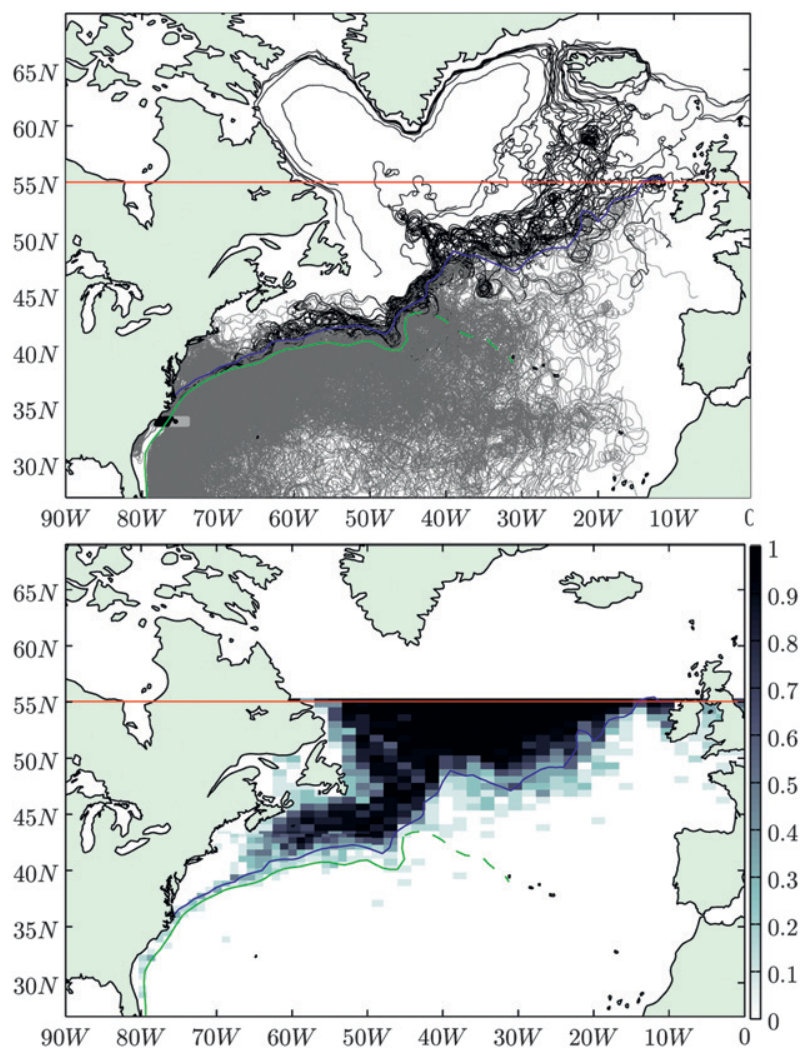

FIG. 15. (top) As in Fig. 4, but for the Ekman-removed system. (bottom) As in Fig. 5, but for the Ekman-removed system.

$$
u_{\mathrm{Ek}}+i v_{\mathrm{Ek}}=\frac{\beta e^{-i \theta}}{\sqrt{f \rho}} \frac{\tau_{x}+i \tau_{y}}{\sqrt{|\boldsymbol{\tau}|}},
$$

where $\tau$ is the wind stress at $10 \mathrm{~m}, \rho=1027 \mathrm{~kg} \mathrm{~m}^{-3}$ is the water density, $f$ is the Coriolis parameter, $\theta=55^{\circ}$ is the rotation angle of the Ekman current, and $\beta=$ $0.065 \mathrm{~s}^{-1 / 2}$ is a dimensional constant.

The resulting Ekman-removed streamfunction $\hat{\psi}_{0}$ in Fig. 14 (bottom) looks qualitatively similar to the Ekman-inclusive streamfunction $\psi_{0}$ in Fig. 14 (top): both show that the subpolar and subtropical gyres are separated by a dividing streamline (black curve) that extends from the hyperbolic (saddle type) stagnation point at North America to the hyperbolic stagnation point at Eurasia. The Gulf Stream lies inside the subtropical gyre and to the southeast from the separating streamline in both configurations. The main differences between the two streamfunctions occur in the eastern part of the subtropical gyre, where the circulation slows significantly when the Ekman component is removed, and in the equatorial region. These differences change the shape of the subtropical gyre such that there is a slight southwest shift of its center. The Ekman-removed streamfunction is consistent with results of Maximenko et al. (2009) and with the latest estimate of mean dynamic topography from the Archiving, Validation, and Interpretation of Satellite Oceanographic data (AVISO) Web site (http:// www.aviso.oceanobs.com/en/home/index.html).

The behavior of the Ekman-removed system with perturbations added is illustrated in Fig. 15. The top subplot of this figure shows 90 simulated trajectories that were released once per month during the 12 months starting in October 1992 within a zonal band straddling the Gulf Stream near $34^{\circ} \mathrm{N}$ and tracked for $2 \mathrm{yr}$; trajectories that crossed $55^{\circ} \mathrm{N}$ are shaded black. Similar to Fig. 3, trajectories released in the easternmost part of the zonal band at $34^{\circ} \mathrm{N}$ are gray. This suggests that at the surface, similar to the Ekman-inclusive system, a transport barrier exists in the Ekman-removed system that prevents fluid originating on its offshore side from entering the subpolar gyre. The main difference between Fig. 4 and the top panel of Fig. 15 occurs in the northeastern part of the subtropical gyre, which is covered less densely by trajectories in the Ekman-removed system.

The bottom panel of Fig. 15 presents a probability map, analogous to that shown in Fig. 5, but constructed for the Ekman-removed system. As before, it shows probabilities that a drifter launched at a particular location will cross a zonal line at $55^{\circ} \mathrm{N}$ within 2 yr. Similar to Fig. 5, the spatial gradient in the probability map near the Gulf Stream core is large, suggesting that the Gulf Stream core still acts as a transport barrier in the Ekman-removed system. A further comparison between Fig. 5 and the bottom panel of Fig. 15 reveals that in the Ekman-removed system the gray region extends slightly farther south between $40^{\circ}$ and $20^{\circ} \mathrm{W}$, allowing drifters that are launched farther inside the subtropical gyre to participate in the exchange with the subpolar gyre.

To summarize, the Ekman velocities serve to slightly suppress the subtropical-to-subpolar fluid exchange (consistent with Brambilla and Talley 2006). However, this should be considered a minor effect since both Ekmanremoved and Ekman-inclusive systems have a qualitatively similar behavior. In both cases, the transport barrier near the Gulf Stream core is present, which limits the exchange to the funnel-shaped area located inshore of the Gulf Stream core.

\section{Summary and discussion}

Motivated by the surprisingly small near-surface drifter exchange from the subtropical to the subpolar gyres in the North Atlantic, we have studied this process using a combination of drifter data, altimetry, statistical analysis, and dynamical systems techniques. Our work builds upon, and is a natural continuation of, prior studies by Brambilla and Talley (2006) and Hakkinen 
and Rhines (2009). However, unlike those papers, we have not confined ourselves to analyzing drifters passing through a particular region of the North Atlantic (such as the Gulf Stream box). Also, we made use of the altimetry-derived mesoscale perturbation velocities rather than the stochastic perturbation, and we have explored both the conventional (statistical) and the more novel dynamical systems (DS) approach.

Our analysis of simulated trajectories in the observationbased system suggests that, over the 2-yr time scale, most of the fluid entering the subpolar gyre can be traced back to a narrow region lying inshore of the Gulf Stream near Cape Hatteras (Figs. 4, 5). (We note here, however, that this conclusion is likely to change if much longer time scales are considered.) Surface fluid on the offshore side of the Gulf Stream is largely prevented from doing so by the Gulf Stream core, which acts as a barrier over much of the eastern North Atlantic. Random seeding of drifters could easily miss the crucial inshore region and lead to a picture with very little exchange between the subtropical and subpolar gyres. The increased number of drifter launches inshore from the Gulf Stream core after 2001 may serve as an explanation for the increased number of drifter crossings after 2001. Our analysis indicates that the transport barrier associated with the Gulf Stream core is robust and holds persistently from 1992 to 2008 during both low and high phases of the North Atlantic Oscillation. The role of Ekman velocities has been investigated, and it was found that the qualitative picture of the major near-surface transport pathways and barriers is largely independent of Ekman drift. The Gulf Stream core in the Ekman-removed system still acts as a barrier and the major pathway leading from the subtropical to the subpolar gyre lies inshore of the Gulf Stream core.

That said, the percentage of our simulated drifters making their way into the subpolar gyre is apparently too small to account for the observed $20 \mathrm{~Sv}$ of northward transport. As a crude guide (recognizing the inequality between drifter exchange and Eulerian transport), the roughly $65 \mathrm{~Sv}$ of Gulf Stream transport near Cape Hatteras (Johns et al. 1995), multiplied by approximately $10 \%$ of drifters that cross, gives only $6.5 \mathrm{~Sv}$. Thus, our work suggests that the bulk of poleward transport should occur at depth. This inference agrees with Brambilla and Talley (2006), who mentioned the necessity of investigating the 3D circulation in the North Atlantic. The enhancement of exchange processes with depth is not a surprising result, because the Gulf Stream weakens with depth, so the associated transport barrier is expected to break down at some level. At that depth, one expects the exchange to increase. This conclusion agrees with the observational studies of Bower and Rossby (1989) and
Bower and Lozier (1994), the modeling work of Lozier and Riser (1990), and the theoretical work of Pratt et al. (1995) and Rogerson et al. (1999), who argue that the Gulf Stream barrier should weaken with depth due to a weakening of its potential vorticity gradient. Modeling results suggest that a level of enhanced exchange occurs where critical lines associated with typical meanders overlap (Yuan et al. 2002; 2004; Lozier and Bercovici 1992). The enhanced exchange at depth was also predicted by the theoretical and modeling studies of Spall (1992), where it is attributed to the cooling in a western boundary current that leads to a counterclockwise rotation of the velocity vector with depth.

Additional insight into the North Atlantic surface fluid exchange, as well as the consistency check for our observation-based model, has been gained from analyzing the GDP surface drifter dataset. In qualitative agreement with the simulated drifters, GDP drifters indicate that the major pathway leading from the subtropical to subpolar gyre goes through a nearshore region in the western part of the North Atlantic, while none of the drifters deployed farther in the interior of the subtropical gyre were able to cross into the subpolar region within their limited lifetimes. We note here, however, that these observational drifters are limited in their ability to mimic fluid movement of the ocean's surface waters since they are restricted to flow in a horizontal plane. Fluid parcels at the surface on the North Atlantic Ocean have no such restriction, and it is likely that vertical movement (subduction) could play a role in enhancing the cross-gyre exchange, as suggested by Brambilla and Talley. Here, in our attempt to explain the observed drifters and in our reconstruction of the observationally based velocity field, our study also necessarily restricts the Lagrangian pathways to the horizontal. A test of the likelihood that three-dimensional motion of subtropical surface waters enhances crossgyre exchange awaits a future study.

Analysis of simulated trajectories with longer integration times indicates that the near-surface fluid exchange between the interior of the subtropical gyre and the subpolar gyre generally occurs on time scales longer than $16 \mathrm{yr}$ and reveals a recirculation region located between Cape Hatteras and Georges Banks that exchanges fluid with subpolar latitudes on the time scale of several years. Trajectories in this region recirculate several times before eventually becoming entrained into the western edge of the Gulf Stream and then rapidly transported to the northeast.

The transport barrier near the GS core has important implications for parameterizing eddy diffusivity and viscosity. It was shown that the two commonly used parameterization techniques, the Visbeck parameterization 
and the Smagorinsky parameterization, result in spuriously large transfer rates in this area.

Our statistical results are complemented by a dynamical systems analysis that supports the overall conclusions. An early goal of the DS approach was to assess its usefulness when applied to a velocity field that contains both large-scale ocean gyres and a mesoscale eddy field. The primary concern is the lack of separation between Eulerian and Lagrangian time scales, a feature desired for the clear identification of hyperbolic trajectories, stable and unstable manifolds, and the like. Despite this formal violation of underlying assumptions, our results yield useful information. The maps of trajectory separation rates (FTLEs) are grainy but clearly show relatively regular motion in the interiors of the subpolar and subtropical gyres, a meandering ribbon forming a barrier corresponding to the instantaneous position of the Gulf Stream, and enhanced stirring around the edges of the Gulf Stream and gyres. The overall geometry is consistent with textbook examples of chaotic advection, and the existence of the barrier at the Gulf Stream core is consistent with, and predicted by, the strong KAM stability argument.

We have focused in this paper on investigating nearsurface transport pathways by which warm and salty water is transported poleward into the subpolar gyre. A complementary problem of finding southward pathways for fresh and cold water would be a natural extension of the work described here.

Acknowledgments. This work was supported by the National Science Foundation Grants CMG-82469600 and CMG-82579600 and by the Office of Naval Research Grant ONR-13108700. We thank the reviewers for a number of helpful suggestions.

\section{REFERENCES}

Bingham, R. J., C. W. Hughes, V. Roussenov, and R. G. Williams, 2007: Meridional coherence of the North Atlantic meridional overturning circulation. Geophys. Res. Lett., 34, L23606, doi:10. 1029/2007GL031731.

Bower, A. S., and H. T. Rossby, 1989: Evidence of cross-frontal exchange processes in the Gulf Stream based on isopycnal RAFOS float data. J. Phys. Oceanogr., 19, 1177-1190.

_ the Gulf Stream. J. Phys. Oceanogr., 24, 1399-1418.

—, H. T. Rossby, and J. L. Lillibridge, 1985: The Gulf Stream-Barrier or blender? J. Phys. Oceanogr., 15, 24-32.

— M. S. Lozier, S. F. Gary, and C. W. Boning, 2009: Interior pathways of the North Atlantic meridional overturning circulation. Nature, 459, 243-247.

Brambilla, E., and L. D. Talley, 2006: Surface drifter exchange between the North Atlantic subtropical and subpolar gyres. J. Geophys. Res., 111, C07026, doi:10.1029/2005JC003146.
Coulliette, C., F. Lekien, J. D. Paduan, G. Haller, and J. E. Marsden, 2007: Optimal pollution mitigation in Monterey Bay based on coastal radar data and nonlinear dynamics. Environ. Sci. Technol., 41, 6562-6572.

Deese, H. E., L. J. Pratt, and K. R. Helfrich, 2002: A laboratory model of exchange and mixing between western boundary layers and subbasin recirculation gyres. J. Phys. Oceanogr., 32, 1870-1889.

d’Ovidio, F., V. Fernández, E. Hernández-Gracía, and C. López, 2004: Mixing structures in the Mediterranean Sea from finitesize Lyapunov exponents. Geophys. Res. Lett., 31, L17203, doi:10.1029/2004GL020328.

—_, J. Isern-Fontane, C. López, E. Hernández-García, and E. García-Ladona, 2009: Comparison between Eulerian diagnostics and finite-size Lyapunov exponents computed from altimetry in the Algerian basin. Deep-Sea Res. I, 56, $15-31$

Gawarkiewicz, G., and C. A. Linder, 2006: Lagrangian flow patterns north of Cape Hatteras using near-surface drifters. Prog. Oceanogr., 70, 181-195.

Hakkinen, S., and P. B. Rhines, 2009: Shifting surface currents in the northern North Atlantic Ocean. J. Geophys. Res., 114, C04005, doi:10.1029/2008JC004883.

Haller, G., 2001a: Distinguished material surfaces and coherent structures in 3D fluid flows. Physica D, 149, 248-277.

- 2001b: Lagrangian structures and the rate of strain in a partition of two-dimensional turbulence. Phys. Fluids, 13, 33653385 .

_ 2002: Lagrangian coherent structures from approximate velocity data. Phys. Fluids, 14, 1851-1861.

— Physica D, 119, 352-380.

Holliday, N. P., and Coauthors, 2008: Reversal of the 1960s to 1990s freshening trend in the northeast North Atlantic and Nordic Seas. Geophys. Res. Lett., 35, L03614, doi:10.1029/ 2007GL032675.

Johns, W. E., T. J. Shay, J. M. Bane, and D. R. Watts, 1995: Gulf Stream structure, transport, and recirculation near $68^{\circ} \mathrm{W}$. J. Geophys. Res., 100, 817-838.

Kuznetsov, L., M. Toner, A. D. Kirwan, C. K. R. T. Jones, L. H. Kantha, and J. Choi, 2002: The Loop Current and adjacent rings delineated by Lagrangian analysis of the nearsurface flow. J. Mar. Res., 60, 405-429.

Lekien, F., and S. D. Ross, 2010: The computation of finitetime Lyapunov exponents on unstructured meshes and for non-Euclidean manifolds. Chaos, 20, 017505, doi:10.1063/1. 3278516.

Lozier, M. S., and S. C. Riser, 1990: Potential vorticity sources and sinks in a quasi-geostrophic ocean: Beyond western boundary currents. J. Phys. Oceanogr., 20, 1608-1627.

_ , and D. Bercovici, 1992: Particle exchange in an unstable jet. J. Phys. Oceanogr., 22, 1506-1516.

Mancho, A. M., D. Small, and S. Wiggins, 2006: A tutorial on dynamical systems concepts applied to Lagrangian transport in oceanic flows defined as finite time data sets: Theoretical and computational issues. Phys. Rep., 437, 55-124.

Maximenko, N., P. Niiler, M.-H. Rio, O. Melnichenko, L. Centurioni, D. Chambers, V. Zlotnicki, and B. Galperin, 2009: Mean dynamic topography of the ocean derived from satellite and drifting buoy data using three different techniques. J. Atmos. Oceanic Technol., 26, 1910-1919.

Olascoaga, M. J., I. I. Rypina, M. G. Brown, F. J. Beron-Vera, H. Kocak, L. E. Brand, G. R. Halliwell, and L. K. Shay, 2006: 
Persistent transport barrier on the West Florida Shelf. Geophys. Res. Lett., 33, L22603, doi:10.1029/2006GL027800.

Poje, A. C., and G. Haller, 1999: Geometry of cross-stream mixing in a double-gyre ocean model. J. Phys. Oceanogr., 29, 1649-1665.

Pratt, L. J., M. S. Lozier, and N. Beliakova, 1995: Parcel trajectories in quasigeostrophic jets: Neutral modes. J. Phys. Oceanogr., 25, 1451-1466.

Ralph, E. A., and P. P. Niiler, 1999: Wind-driven currents in the tropical Pacific. J. Phys. Oceanogr., 29, 2121-2129.

Rogerson, A., P. D. Miller, L. J. Pratt, and C. K. R. T. Jones, 1999: Lagrangian motion and fluid exchange in a barotropic meandering jet. J. Phys. Oceanogr., 29, 2635-2655.

Rypina, I. I., M. G. Brown, F. J. Beron-Vera, H. Kocak, M. J. Olascoaga, and I. A. Udovydchenkov, 2007: On the Lagrangian dynamics of atmospheric zonal jets and the permeability of the stratospheric polar vortex. J. Atmos. Sci., 64, 3593-3610.

— — - and H. Kocak, 2009: Transport in an idealized threegyre system with an application to the Adriatic Sea. J. Phys. Oceanogr., 39, 675-690.

_ , L. J. Pratt, J. Pullen, J. Levin, and A. Gordon, 2010: Chaotic advection in an archipelago. J. Phys. Oceanogr., 40, 1988-2006.

Samelson, R. M., and S. Wiggins, 2006: Lagrangian Transport in Geophysical Jets and Waves: The Dynamical Systems Approach. Springer-Verlag, $147 \mathrm{pp}$.

Sevryuk, M. B., 2007: Invariant tori in quasi-periodic nonautonomous dynamical systems via Herman's method. Discrete Contin. Dyn. Syst., 18, 569-595.
Shadden, S. C., F. Lekien, and J. E. Marsden, 2005: Definition and properties of Lagrangian coherent structures from finite-time Lyapunov exponents in two-dimensional aperiodic flows. Physica D, 212, 271-304.

— J. D. Paduan, F. P. Chavez, and J. E. Marsden, 2009: The correlation between surface drifters and coherent structures based on high-frequency radar data in Monterey Bay. Deep-Sea Res. II, 56, 161172.

Smagorinsky, J., 1963: General circulation experiments with the primitive equations. 1 . The basic experiment. Mon. Wea. Rev., 91, 99-164.

Spall, M. A., 1992: Cooling spirals and recirculation in the subtropical gyre. J. Phys. Oceanogr., 22, 564-571.

—, R. S. Pickart, P. S. Fratantoni, and A. J. Plueddermann, 2008: Western Arctic shelfbreak eddies: Formulation and transport. J. Phys. Oceanogr., 38, 1644-1668.

Stommel, H. M., and A. B. Arons, 1960: On the abyssal circulation of the World Ocean-I. Stationary planetary flow patterns on a sphere. Deep-Sea Res., 6, 140-154.

Visbeck, M., J. Marshall, T. Haine, and M. Spall, 1997: Specification of eddy transfer coefficients in coarse-resolution ocean circulation models. J. Phys. Oceanogr., 27, 381-402.

Yuan, G.-C., L. J. Pratt, and C. K. R. T. Jones, 2002: Barrier destruction and Lagrangian predictability at depth in a meandering jet. Dyn. Atmos. Oceans, 35, 41-61.

,-- , and,- 2004 : Cross-jet Lagrangian transport and mixing in a 2 1/2-layer model. J. Phys. Oceanogr., 34, 19912005. 